\title{
Research on the Promotion Path of Marketing Strategy of Sci Tech Journals from the Perspective of Media Convergence
}

\author{
Wenlan Chen', Yuan Chen ${ }^{2}$ \\ ${ }^{1}$ Journal Editorial Department of Zhejiang University of Water Resources and Hydropower, Zhejiang University of Water \\ Conservancy and Hydropower Technology, Hangzhou, China \\ ${ }^{2}$ Editorial Department of Distance Education Journal of Zhejiang Open University, Hangzhou, China \\ Email: chy0501@126.com
}

How to cite this paper: Chen, W.L. and Chen, Y. (2021) Research on the Promotion Path of Marketing Strategy of Sci Tech Journals from the Perspective of Media Convergence. Open Access Library Journal, 8: e7134.

https://doi.org/10.4236/oalib.1107134

Received: January 5, 2021

Accepted: March 23, 2021

Published: March 26, 2021

Copyright $\odot 2021$ by author(s) and Open Access Library Inc.

This work is licensed under the Creative Commons Attribution International License (CC BY 4.0).

http://creativecommons.org/licenses/by/4.0/

\begin{abstract}
The concept of media convergence development is fully presented in various fields of sci-tech journals, and it also provides power and technical support for the reform of marketing of sci-tech journals. Based on the background of media fusion and marketing strategy in sci-tech periodicals, this paper discusses the challenges, strategies and ideas of marketing strategy of sci-tech periodicals under the perspective of media fusion, analyzing the challenges such as the problem of publishing and issuing, the bottleneck of media fusion marketing means, and putting forward the situation of positioning differentiated service groups, integrating outstanding periodical resources and the deep fusion strategy of new media and marketing channels at two levels. Sci-tech periodicals should actively use big data to formulate precise services and "customer first" concepts for providing differentiated services, build a cluster development platform for sci-tech journals, expand distribution channels by leveraging WeChat technology, and promote full-text HTML formatting to help spread the technology and business level throughout, connect with the counterpart industry and set up an online new media communication model to promote its integration with the organic end.
\end{abstract}

\section{Subject Areas}

Journalism and Communication

\section{Keywords}

Sci-Tech Periodicals, Media Integration, Supply Side Reform 


\section{Introduction}

In the era of pre media convergence, the development of paper-based sci-tech periodicals is difficult because of its single channel of communication and management, and the restriction of the demand side of digital publishing on the supply side is also the main driving force for its marketing strategy reform. Most Sci-tech Journals only focus on the first step in the process of periodical knowledge service, from periodical publishing to readers' purchase and sale, and then to readers' reading. However, from the perspective of supply and demand, these three steps are important work areas for inspecting the service quality of Sci-tech Journals [1]. The diffusion effect of paper media and communication channels is in the downward stage, which urges the traditional journals to change their inherent development trajectory and explore a new multi-channel marketing mode of media convergence development.

\section{In the Context of Media Convergence, the Marketing of Sci-Tech Journals Is Facing Many Challenges and Measures}

\subsection{The Dilemma of Publishing and Distribution of Sci-Tech Journals in the Context of Media Convergence}

\subsubsection{The Impact of Selective Reading on Publishing}

The widely used and easy-to-use form of keyword retrieval for selective reading makes it difficult for the traditional way of intellectual copyright protection to adapt to the requirements of the new situation. The intellectual copyright protection of academic works has become a thorny problem, and the exclusive copyright has existed in name, [2] in order to expand the popularity of published articles and journals, it has become normal for the same paper to appear in different media at the same time, but the mature open access publishing order in China has yet to be cultivated and established, which leads to the loss of traditional publishing advantages of scientific journals.

\subsubsection{The Construction of Marketing Team of Sci-Tech Periodicals Needs to Be Improved}

Journal publishing needs a professional marketing team, and nurturing advanced marketing ideas and planning ideas is a strong support to improve marketing performance. Due to the constraints of administrative approval and operation system of sci-tech journals, personnel and hardware equipment are limited, technical strength is weak, human and material resources are limited, and there is a lack of high-quality professional marketing team This paper analyzes the dilemma of digital marketing of Sci-tech Journals [2] [3] [4].

\subsection{Bottleneck of Media Convergence Marketing}

\subsubsection{The Construction of the Website Is One-Sided and Lacks Marketing Function}

Website appearance, mode and function are similar, lack of marketing features, lack of innovative personalized marketing services, showing the monotonous 
content presentation phenomenon. The user interaction and experience of the website is low, and the operation is lack of continuous investment and timely update. To sum up, these problems are due to the lack of attention to "user thinking" in the design concept of the website platform, blind imitation, no in-depth planning of journal marketing and the functional positioning and interactive integration of the website, just to build the website [4] [5], and no consideration from the perspective of deepening and broadening the consumer group.

\subsubsection{Slow Progress of Network Marketing Development}

As a result, the lack of knowledge and operation mechanism of network marketing not only leads to the lack of professional development and operation mechanism, but also leads to the lack of network marketing platform The attachment of publishing information limits the full play of the dual effects of new media and communication marketing, and it is unable to establish a three-dimensional marketing pattern of integration and interaction between scientific journals and new media [4] [5] [6].

\subsubsection{Lack of Marketing Precision Knowledge Service Concept}

Due to the lack of high awareness of accurate service for consumer groups, the failure to correctly analyze the new situation of publishing and distribution, the lack of driving force to optimize the marketing structure, the neglect to examine their own marketing strategies, and the passive approach to the new media trend. The focus of consumer groups targeted by Sci-tech Journals is not clear [5] [7] [8]. Most of the consumer groups of university journals have no professional differentiation, and they are basically "large and comprehensive" audiences, so it is obviously difficult to attract fixed professional groups to consume.

In order to face the current grim situation and expand the audience level and consumer groups of sci-tech periodicals, first, we must rely on the platform of the dissemination and marketing of new media. Second, we will use WeChat platform and official account to establish a new mode of publishing and marketing services with internet attributes. Third, we should enhance the interaction between sci-tech journals and authors, optimize the continuous high-quality content output around the precise needs of consumer groups, explore and fully adapt to the changes of the new trend, and build a more mature marketing operation model framework.

\section{Marketing Ideas of Sci-Tech Journals in the Context of Media Convergence}

\subsection{Formulate Differentiated Service Path}

\subsubsection{Develop User Precise Service with Big Data}

Depending on the number of QR code scanning users, regional distribution, time period and other data, we can accurately locate the customer groups and types, accurately calculate the types of customer information needs, and even predict the time period of customer information needs. Then, according to the statistical data, we can carry out the controlled issuance strategy, and accurately 
select specific types of information for existing, important, and potential customers Delivery time, improve the later push effect. Whether we can make full use of big data technology is the key point to implement the customized and accurate push of the business.

In the big data environment, people's access to information has shifted from extensive search to efficient interception. Fast, convenient and accurate knowledge acquisition is the ultimate construction goal of the service demand side. It can help readers accurately complete the target screening, advance the reader service, optimize the access to knowledge, and improve the smoothness of the supply channel through big data survey from the perspective of population and emotion, we should focus on the psychological characteristics of improving students' academic performance and entrance examination, and open our own exclusive market.

\subsubsection{Highlight the Concept of "Customer First"}

Expand personalized and private customized services, such as associating users' wechat with sci-tech journal editing system, pushing review information and page fees to authors through Wechat, pushing review tips to reviewers, and pushing latest published papers of related majors to specific readers. Journals should facilitate the authors to obtain citation information and find potential academic partners in time, connect with the open citation service platform of Chinese Science Citation Database (CSCD), push citation data service for platform users, and integrate website platform content into CSCD database system.

\subsection{Building a Cluster Development Platform for Sci-Tech Journals}

Integrated development is the development trend of establishing the brand banner of journals, and digital public platform is the hot spot of journal group construction. Through the unified digital platform, professional clusters and journal group alliance are established, and the database with academic professionalism and scale is constructed. The basic elements of journal group operation are scale and operation right, and convenient and accurate access to search content is the core element of journal group construction, which strengthens the matching and exclusiveness of retrieval, and strengthens the reader stickiness at the same time.

The maturity of digital publishing platform technology can fully support large-scale high-quality journals to be closely "bundled" together, and jointly establish a service platform, such as writing mobile terminal journal app software, presenting all kinds of journal content of alliance to readers on a platform, which not only improves the popularity of the service platform, but also plays the role of cooperation of various journals to attract readers The ability to do so.

Journal of water conservancy is a comprehensive journal of water conservancy, modern food science and technology is a core journal of food industry, Guangdong agricultural science is a comprehensive agricultural journal, southern fisheries science is a professional journal of animal husbandry and fisheries, and so on. There are 17 kinds of journals in five major scientific and technologi- 
cal fields. The collaborative development mode of journal group of water, agriculture, environment and food engineering can be set up, and the management of journal group can achieve the goal of strong linkage effect.

\subsection{The Path of Technology and Operation}

\subsubsection{Using Wechat Technology to Expand Distribution Channels}

By customizing the two-dimensional code for each paper, readers can scan the two-dimensional code anytime and anywhere, download the paper, browse anytime and anywhere, help reprint and spread mobile reading, realize the real mobile and fragmented reading, and add words to express their views at the bottom of the paper according to their feelings after reading, and interact with editors and authors. By scanning the QR code on the mobile terminal, the author can view the publication of the paper, the payment of online layout fee and other additional information.

With the support of cloud technology with huge storage capacity, the file content can be transmitted by the flexible scanning entrance of QR code, and the content can be updated directly in the cloud. It is necessary to respect the feelings and values of the user experience, push good content, and realize online interaction through Wechat subscription number to praise, praise, and leave messages for the communicators. Online interaction is a supplement to offline interaction, which can be realized from and let Wechat subscription number closer to readers, realized the "fission type" communication effect.

\subsubsection{Promote Full Text HTML Formatting to Help Spread}

In order to realize the structured and fragmented reading of content data, some journals have begun to pay attention to the full universal text. This paper is used to complete the convenient download, copy and fragmentation extraction [6] [9]. Relying on the professional editing talent team, the full-text HTML format of the paper is produced under the highly information technology of the Internet, which extends the functional span of semantic publishing and enriches the relevance ability of semantic database; under the reading habit of jumping and fragmentation, it is very easy to quickly and accurately grasp the program and interest points from the massive information, which increases the intimate experience and implements the semantic library The concept of interactivity.

In the homepage of the official website of the journal, "HTML" link is provided under the title of each article. The content of each part of the article is fragmented by HTML format, and each paragraph and chart are summarized and extracted separately. After shallow reading, readers can directly click on the content of interest points for deep reading, so as to save the whole search effort and improve the reading efficiency.

\subsection{The Path of Organic Combination with New Media}

\subsubsection{Linking up the Corresponding Industries and Improving the Economic Benefits of Periodicals}

Academic resources have important guiding advantages for the guidance and 
development of its counterpart industry. Sci tech journals set up counterpart professional industry websites, and use professional industry chain to enhance the attention and advertising volume of portal websites. It is a good way for sci-tech journals to optimize the marketing strategy of journal operation mechanism by driving industry development and expanding and upgrading industry technology exchange platform the way of economic feedback. Micro-blog, WeChat official account platform mobile phone App client can copy this mode of operation, which enhances user experience and attracts industry professionals' attention and broadens the audience.

For example, China Modern Traditional Chinese medicine, by leading the traditional Chinese medicine industry, collects the latest information for practitioners of traditional Chinese medicine production, processing, sales and service, drives traditional Chinese medicine resources to become the leading industry in Hubei and Hunan, continuously improves the overall attention of the journal, and also attracts more high-quality manuscript sources. The editorial department is rated as "the second demonstration case unit of integrated development of Journals".

\subsubsection{Open Multimedia Communication Mode to Enhance User Experience}

The authors of major research achievements are invited to participate, and video and audio communication services aiming at the theme or its extension direction are opened on the new media platform of the journal. Readers are encouraged to publish the actual process of research by means of video, audio and other multimedia means, and "face-to-face" questions on the content of interest and uncertain results, so as to carry out one-to-one interaction with the authors. This model reflects the characteristics of "private customization" service, and provides readers and authors with "zero distance" face-to-face contact opportunities to fully meet the personalized needs of readers.

The video recording of interview with academicians of Chinese Academy of engineering is provided by China Coal journal network, which is rich in content. Among them, the "scientific research direction planning" is analyzed and discussed in combination with copywriting examples, and has won the unanimous praise of readers. In the later stage, the videos of direct interview with journal editors and participation in recording are successively launched, and the videos are also recorded and provided by experts according to the questions raised by the editorial department.

\section{Marketing Strategies of Sci Tech Journals in the Context of Media Convergence}

\subsection{Positioning Differentiated Service Groups}

Under the background of networking and declining business performance, the vague and repetitive positioning of the audience category of sci-tech journals has been replaced by the strategy of accurate segmentation of market target posi- 
tioning [6] [7]. The audience of sci-tech journals is mainly composed of three dimensional groups: teachers and students, academic researchers and front-line practitioners. In order to establish a unique journal positioning, and different from pure academic or pure commercial journals, the effective strategic goal is not only to shape the connotation and atmosphere of academic research, but also to integrate into the practical trend doctrine, so as to create a sci-tech journal with characteristics and high market competitiveness. Therefore, in order to establish a higher brand awareness in the same kind of Sci-tech Journals in this professional field, it is necessary to have both theoretical height and unique positioning close to the market.

\subsection{Integration of Excellent Periodical Resources and Intensive Development}

Compared with the mature construction experience of Foreign Sci-tech Journals (such as American Chemical Society, American Mathematical Society, Royal chemical society, etc.), the cluster cooperation level of domestic sci-tech journals is still in the initial exploration and simple imitation stage [8] [9]. The biggest problem is how to realize the collectivization and networking, and make full use of the integration platform of two micro and one network to integrate journals Resource integration, concentration of industry advantages, or vertical or horizontal joint to enhance the strength of the journal. For example, the journal group of Chinese Medical Association (with more than 100 kinds of medical journals) has not only learned from the operation mode of foreign countries, but also created a new situation of catering to local academic services [7] [8] [9].

\subsection{Integration of New Media and Marketing Channels}

\subsubsection{Penetration of Technology and Operation}

Marketing content integration includes online and offline, text and video animation, audio; marketing channel integration includes online and offline, traditional and emerging, direct and indirect, text sales and information publicity; marketing terminal integration includes offline and online, broad spectrum and precision, readers and authors [7] [8] [9] [10]. Semantic publishing, intelligent interaction, visualization and other new technologies have strong guidance for the future publishing pattern of sci-tech journals. With the continuous penetration and evolution of digital and Internet technology in the field of sci-tech journal publishing, a more efficient, lower cost and more interactive marketing mode are collided. This marketing mode strengthens the interactive mode of user and audience viscosity, and improves the consumption efficiency The loyalty of the customer.

\subsubsection{Organic Combination with Content, Channel and Terminal of New Media}

As an important key link in the success of marketing strategy, the management of periodicals has also become the entry point of media convergence. The tech- 
nology change of emerging media reconstructs the new normal of sci-tech journal publishing, the new media platform improves and replaces the traditional platform, and the three-dimensional vertical marketing mode subverts the old single level publishing marketing strategy. Sci tech journals organically integrate the technology of traditional paper media and new media, and form a good interaction with their supply side optimization through the operation and publishing mode [9] [10].

The journal group construction can imitate the institutional framework model, integrate multi-directional and multi-level resources through cluster management, and form its own unique structure mechanism; the management needs to be all networked, which is conducive to the participation of readers and authors; the business should explore diversified profit support points, not only to meet the additional requirements of the author, but also to reserve profits for the future construction growth engine.

The entry point of media convergence provides a vast space for upgrading information marketing means, and forms a virtuous circle interaction with the expansion of multi-channel marketing mode.

\section{Conclusions}

With the large-scale application of journal website, online manuscript review and editing system, digital products, digital publishing and digital operation emerge as the times require; based on the updating iteration of microblog, Wechat public platform and independent app development form in today's mobile Internet atmosphere. Marketing is an important reference scale to support the sustainable development and influence of sci-tech journals. The concept of media integration development is fully presented in various marketing fields of sci-tech journals, and it also provides power and technical support for the reform of marketing strategy of sci-tech journals. In the context of big data era, to enhance the innovation and competitiveness of marketing service of sci-tech journals is the breakthrough to determine whether journals can improve marketing performance; the multi-point, multi-faceted and multi-level new media marketing channels are all to enhance the service value of Sci-tech Journals through marketing strategies.

There are a large number of Sci-tech Journals in China, with complete types, stratified quality and significant differences in spatial distribution. Therefore, the research on the marketing strategy of current sci-tech journals should consider the influence of different economic bases, cultural accumulation, scientific research strength and other factors on the agglomeration degree of academic journals. Starting from the effect of cluster, this paper makes full use of the analysis advantages of current big data to analyze its marketing measures and strategies. This is also the limitation of this study, which needs to be improved in the future research.

\section{Fund Project}

This paper is the research results of 2020 scientific research project "recon- 
struction of academic journals' credibility from the perspective of Omnimedia (ZGXB202001)" by Zhejiang Provincial Journal Association, Zhejiang Higher Education Association.

\section{Conflicts of Interest}

The authors declare no conflicts of interest regarding the publication of this paper.

\section{References}

[1] Ji, H.T., Guo, Y.M., Guo, X.L., et al. (2015) New Development Mode of Sci-Tech Journals under the Background of Media Convergence. Research on Chinese Sci-Tech Journals, 26, 60-64.

[2] Zhang, Y.P. (2015) Development Mode of Cross Media Integration of Sci Tech Journals: A Case Study of Journal of Architecture. Research on Chinese Sci Tech Journals, 26, 600-606.

[3] Chen, X.F., Yun, Z.J., Wan, X.X., et al. (2017) Marketing Strategy of Sci-Tech Periodicals Promoted by Media Convergence Precision Knowledge Service. China Sci Tech Periodicals Research, 28, 805-809.

[4] Fan, Y.M. and Liu, G.Z. (2017) Integrated Development and Intensive Management of Sci-Tech Journals: The Development Trend of Sci-Tech Journals under Media Integration. China Sci Tech Journal Research, 28, 340-343.

[5] Zhou, B.Y., Duan, C.B., Yu, P., et al. (2013) Opportunities and Challenges for Sci Tech Journals in the Era of Media Convergence. Friends of Editors, No. 4, 35-37.

[6] Guo, Y.M., Guo, X.L., Ji, H.T., et al. (2014) Innovation of Sci Tech Journals in the Context of Media Convergence. Acta editorialis Sinica, 26, 521-525.

[7] Zhang, Y. (2017) New Media Convergence of Sci Tech Journals Based on "H5 + Wechat". Research on Chinese Sci Tech Journals, 28, 936-940.

[8] Chen, X.F., Yun, Z.J. and Wan, X.X. (2017) Media Convergence and Accurate Knowledge Service Promote the Supply Side Reform of Academic Journals. Journal of Science and Technology of China, 28, 805-809.

[9] Zhang, W.W., Li, Y., Zhao, W.Y., et al. (2017) Marketing Strategy of Sci-Tech Periodicals Promoted by Media Convergence Precision Knowledge Service. China Sci Tech Periodicals Research, 28, 151-155.

[10] Liang, H. and Chen, L.Q. (2017) How Industry Journals Survive in Adversity in the New Media Era. China Publishing, No. 11, 46-49. 